\title{
Artificial Intelligence, Smart Contract and Islamic Finance
}

\author{
Siti Rohaya Mat Rahim ${ }^{1}$, Zam Zuriyati Mohamad ${ }^{2}$, Juliana Abu Bakar ${ }^{1}$, Farhana Hanim Mohsin ${ }^{3}$, \& Norhayati Md \\ $\mathrm{Isa}^{3}$ \\ ${ }^{1}$ Department of Economics, Faculty of Business and Finance, Universiti Tunku Abdul Rahman, Perak, Malaysia \\ ${ }^{2}$ Department of Commerce \& Accountancy, Faculty of Business and Finance, Universiti Tunku Abdul Rahman, \\ Perak, Malaysia \\ ${ }^{3}$ Department of Business, Faculty of Business and Finance, Universiti Tunku Abdul Rahman, Perak, Malaysia \\ Correspondence: Siti Rohaya Mat Rahim. E-mail: rohaya@utar.edu.my
}

Received: January 1, 2018

doi:10.5539/ass.v14n2p145
Accepted: January 16, $2018 \quad$ Online Published: January 29, 2018

URL: https://doi.org/10.5539/ass.v14n2p145

\begin{abstract}
This study examines the two important aspect of latest technology issues in Islamic finance that related to artificial intelligence (AI) and smart contract. AI refers to the ability of machines to understand, think, and learn in a similar way to human beings, indicating the possibility of using computers to simulate human intelligence. Smart contract is a computer code running on top of a block-chain containing a set of rules under which the parties to that smart contract agree to interact with each other. The main objectives of this article is to evaluate the operations of AI and smart contract. Our study also highlights the comparison between the operations of AI and smart contract. This article concludes that $\mathrm{AI}$ and smart contract will have a huge impact in future for Islamic Finance industry.
\end{abstract}

Keywords: Artificial intelligence (AI), smart contract, digital banking, Islamic Finance

\section{Preliminary}

Artificial Intelligence (AI) is the intelligence machines that have the ability to think. At this point, Artificial Intelligence (AI) offers rapid advancement in technology that mimic human intelligence. It's believed that intelligence machines associated with human thinking activities such as decision making and problem solving learning. Professor J. McCarthy (1955) established the concept of artificial intelligence (AI) during the first artificial intelligence conference at Dartmouth conferences in year 1956. This evolution confirm by Bogue (2014) who described Artificial intelligence (AI) as an intelligent agent system that takes actions in maximize the chances of success in a particular task. Pan (2016) revealed that AI becomes extremely critical when it applies to the technology. According to research report on artificial intelligence, this market is expected to be worth $\$ 16.06$ billion by 2022. This market is expected to grow at 62.9\% compound annual growth rate (CAGR) from 2016 to 2022 (Research and Markets, 2017). In 25th April 2016 to $27^{\text {th }}$ May 2016, a special report under the subheading "Outlook on Artificial Intelligence in the Enterprise 2016" have been produce by Narrative Science in collaboration with National Business Research Institute. This report deployed an online survey with a total of 235 respondents. The result clearly show that $58 \%$ of the respondents believe that AI should be capable of doing predictive analytics in many cases. This includes the uses of data mining, statistics, modeling and machine learning. Perhaps more importantly, it is estimated that the market for big data technology and services will reach to $\$ 48.6$ billion by 2019 (Narrative Science, 2016). A recent paper by Abdullah (2017) indicate that artificial intelligence, digital bank 4.0 and FinTech banking have shown the potential application since year 2017 (Figure 1). Abdullah (2017) stated that we currently in the era of artificial intelligence, Islamic Fintech and Digital Bank 4.0.

These days, as customers become more sophisticated and knowlegable, they prefer to make their financial transactions with less human interaction. The scope of technology is much wider and has the potential to improve the overall financial system efficiencies. One of the popular tools is the smart contract, a computer programme that can execute contract terms (Idelberger, Governatori, Riveret, \& Sartor, 2016). Fully automated, smart contract can either complement or fully substitutes typical legal contracts. This is apparent since smart contracts are becoming crucial in several industries like healthcare, real estate and securities. There are some other possible applications such as in banking systems, insurances, management and others. Formulated as any 
other technology and innovation driven, the smart contract and artificial intelligence might be adopted in some Islamic banking products. Whilst, Kmeid (2017) found that AI is capable of creating machine learning tools and deep neutral networks which can bring a whole new experience to the finance industry.

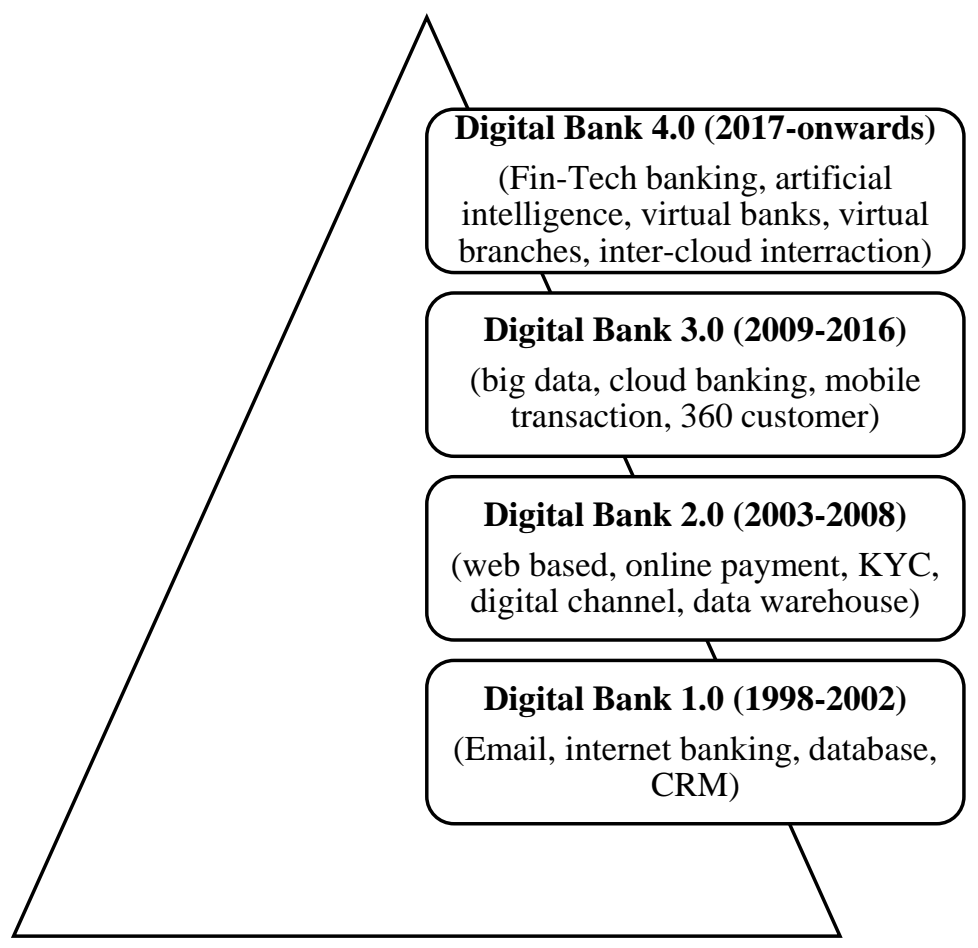

Figure 1. Digital Banking Evolution

This study examines the two important aspects of the latest technology issues in Islamic finance that relates to artificial intelligence (AI) and smart contract. The objectives of this study are three-fold: first, to evaluate the operational of artificial intelligence (AI) and smart contract, second, to make some comparison on the operational of artificial intelligence (AI) and smart contract. Third, to elaborate the advantages between the two.

This article is organized as follows. A literature review is provided of which is followed by a discussion on the application of artificial intelligence and smart contract. Afterwards, the pros and cons of adopting artificial intelligence and smart contract have been review. At last, this research presents the conclusion and some recommendation.

\section{Literature Review}

Hassabis et al. (2017) study the fields of neuroscience and artificial intelligence (AI). They recognized the need to understand how biological brains works could be the best solution in building intelligent machines. The key idea is to study the interactions between the AI and neural computation in humans. Hamet and Tremblay (2017) describe the application of AI in medicine. This AI has boosted in genetics and molecular medicine, treating chronic mental diseases and to update the medical records (family history of a hereditary disease or a chronic disease). It revealed that $\mathrm{AI}$ is rapidly developing in few field like military, security, transport and manufacturing. Khan (2017) identifies that AI is useful for bank and financial institutions through the development called "robo advisors". Advancement in "robo advisors" is particularly important because it can act as an automated financial advisors which helps the user to make their financial decisions (i.e. personal financial management). She admitted in times to come, AI will move towards financial analysis, asset allocation, insurance underwriting, forecasting and reporting due to its unique features related to speed and accuracy.

Pan (2016) wrote that several firms that are currently adopting artificial intelligence (AI) in particular projects. However, most of the investments and initiatives were also in its infancy stage. According to Pan (2016) Microsoft developed the chatting robot known as Xiaobing. Meanwhile, IBM developed the Watson system. This system facilitates the screening of the historical records of the cancer patient in many hospitals. Elsewhere, in China, Baidu continues to focus on developing platforms for smart devices as well as AI into financial services sectors. Among other things, this paper acknowledged the efforts done by the Chinese Academy of Engineering. The reason for this, Chinese Academy of Engineering turn current systems into intelligent cities, big data, 
manufacturing, innovative design and the digital creative industry. In the end, Pan (2016) has urged closer strategic collaboration between scientists and think tanks. This collaboration is important to ensure further development of AI technology.

Alzaidi and Kazakov (2008) proposed the artificial intelligence approach to improve the tawarruq process based on the existing system. They suggested that the supply chain should manage the data flow and links it to the variety of supply chain network participant (e.g. borrowers, banks, suppliers and warehouse). This system allows each agent in the network to control its own bank account to make money transfers easy and just in one click. Alzaidi and Kazakov (2008) also promoted tawarruq via international brokers and international markets. The bank adds a profit on the total and then resell the products on their behalf. Then, the bank will contacts the broker once again to resell the products for the borrowers.

Dirican (2015) clarifies that not only artificial intelligence but also considers, semantic studies, robotics and mechatronics developments, big data, data mining, cloud computing and neural networks as the main trends that leads to future directions of banking and financial services. A research done by Dirican (2015) acknowledged that robots use huge amounts of information called big data from many databases or connected to cloud computing and are managed by artificial intelligence. The suggestion could be for production lines and the human resource agenda.

A closer analysis by Giancaspro (2017) postulates that a smart contract might be programmed to purchase a particular item at a certain price. This contract should include the product warranties. The novel application of smart contracts is said to be an important element rather than the vendor being connected to the purchaser's personal and financial information via a trusted intermediary, as the system is commonly connected directly to the purchaser's digital wallet. Giancaspro (2017) even expressed that this smart contract could lead to identifying parties in the contract, the deadline for reference to the exchange price of stock, the pre-conditions and the logic for execution of the program as framed by the pre-conditions.

Savelyev (2017) paper analyzes the key element between a traditional contract and a smart contract. The author defines the smart contract as "agreements existing in the form of software code implemented on the Blockchain platform". The nature of the smart contract is based on a predetermined set of factors. Mik (2017) discusses the problems of integrating this smart contract with the real world. This paper proposed some technological and legal constraints of the smart contract's functions. Nevertheless, Mik (2017) demonstrates that smart contract is suitable for banks, lawyers and courts.

Szabo (1997) who is the founder of the smart contract, introduced the idea that by utilizing protocols and user interfaces will facilitate all steps of the contracting process. This smart contract is far more functional than the traditional contract. According to Szabo (1997) smart contracts will facilitate many financial services, typically for installment loans and credit cards. He believes that smart contracts have the potential to support many industry such as banking, insurance, energy, e-government, telecommunication, music and film industry, art, education and many more.

\section{Application of Artificial Intelligence}

Financial institutions are looking ways to deploy chatbots to handle day-to-day banking tasks in appearance of 24/7 customer services activities. In most cases, chatbots offer services for personal financial management (PFM) and wealth management. Chatbots cover several functional areas including:

i. Customer Services: Answering simple question from call centres, reporting the lost card and re-setting the PIN number.

ii. Product sales: Chatbots helping in identifying or grouping customer according to the banking products.

iii. Transaction: Assist in fund transfer between account, paying bills and checking account balance.

The simplest chatbot process flow is shown in Figure 2. The main process of chatbot start with the initial pre-processing of the user's text. This step require the input text to be converted into speech-to-text (S2T) or text-to-text (T2S). A step further required the speech-to-text (S2T) or text-to-text (T2S) to be converted into natural language processor. Natural language processor tasks typically involved the direct hand coding. The process continue to generate a large input data extracted from the users in a structured way.

Through machine learning, a bot can review chat histories to augment conversational abilities for financial institution and clients. Very simple reply of the conversation will be created to answer the best matches of the user statement. The post-processing is needed to ensure the chatbot system isn't perform badly. The interface connector are supported via Skype, WeChat, WhatsApp, Facebook messenger etc. 


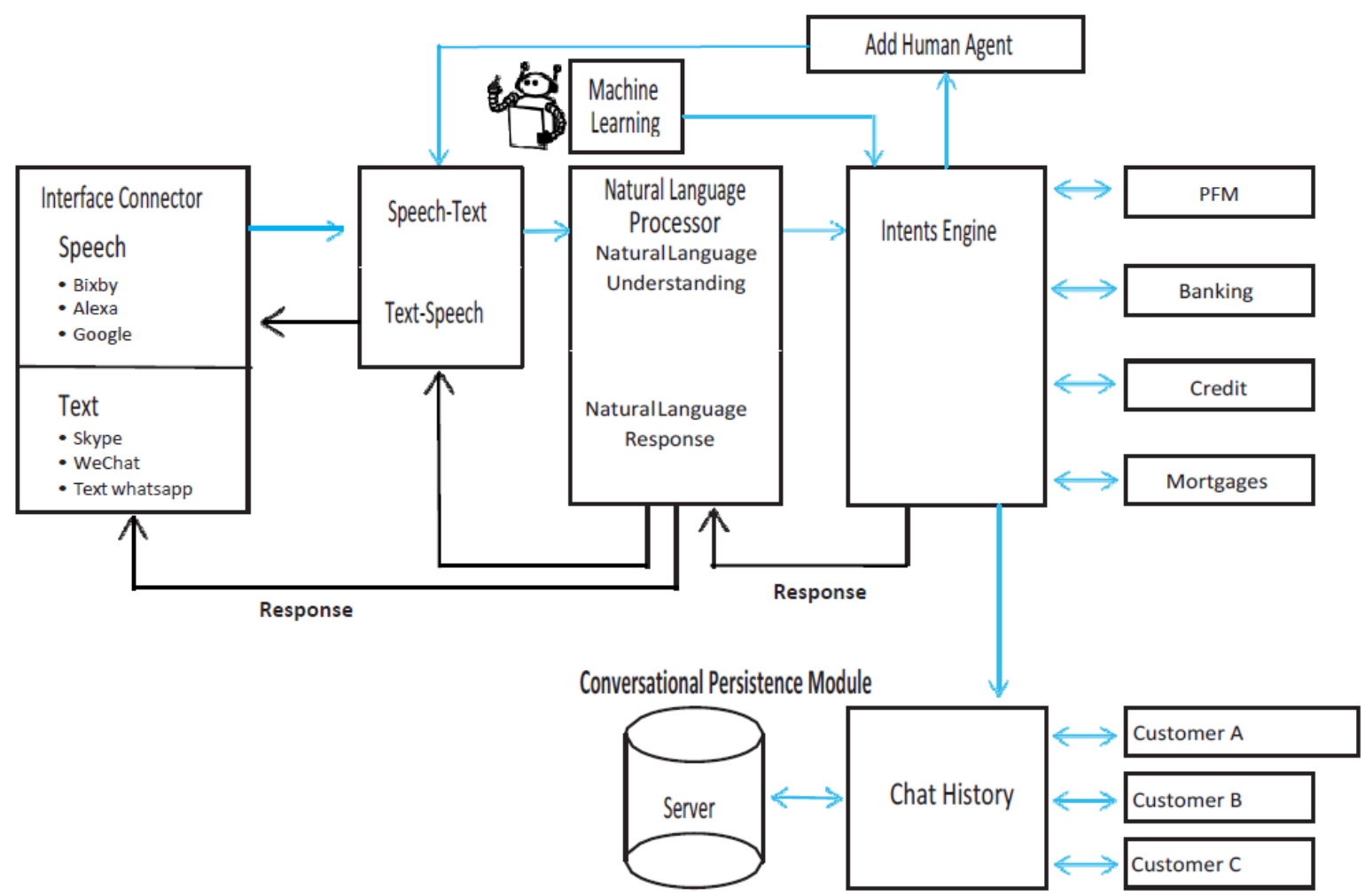

Figure 2. Chatbot process flow

The next three scenario depicts the application of Artificial Intelligence (AI) in banking, which is as follows:

\section{Scenario 1}

Concurrently, the Canada's Big Five banks are using AI chat-bots that interact with customers through the bank's digital channels (online, mobile and social media). Based on a pilot project the Royal Bank of Canada has been testing programmable software bots that can perform administrative tasks such as processing mortgage applications and insurance claims processes (Ligaya, 2017).

As a 'living' example of how artificial intelligence can be utilized in financial services, Hong Leong Bank's A.I. chat service took a first step towards introducing a new channel for customer interaction via live chat function, which is available on the Hong Leong Bank Corporate Website. Figure 3 displays how Hong Leong Bank's A.I. chat advisor look's like in a real conversation. Hong Leong Bank's A.I. chat advisor makes the banking conversation smarter and more convenient.

The A.I. chat advisor is able to answers customer's banking questions on topics such as credit cards, fixed deposit, current and saving account, personal loan, mortgage loan, auto loan etc. This customer chat service are designed to carry out pre-scripted conversations. It also has the capabilities to handle any customer inquiry by providing customer support from start to finish. When necessary, it can even schedule an appointment via the phone according to the customer's preferred date and time.

Inspired by artificial intelligence technology, RHB bank have introduce personal loan application processing platform through Chatbot. The chatbot system is the result of a collaboration between RHB bank and financial comparison website RinggitPlus. Consumers can now apply for their personal loan via Chatbot on RinggitPlus.com and they will obtain the results within a day via SMS. RHB bank is targeting to grow its personal loan disbursement by $60 \%$ to RM60 million by 2018 via Chatbot. Meanwhile, CIMB bank seek to assist customers in mobile application called CIMB EVA to manage user's daily banking needs. To used CIMB EVA customer need to have a valid CIMB Clicks User ID and a mobile device running either iOS 8.1 and above or any Android 4.1 and above. With CIMB EVA customer easily check their account balances, paying bills and reload prepaid phones. 


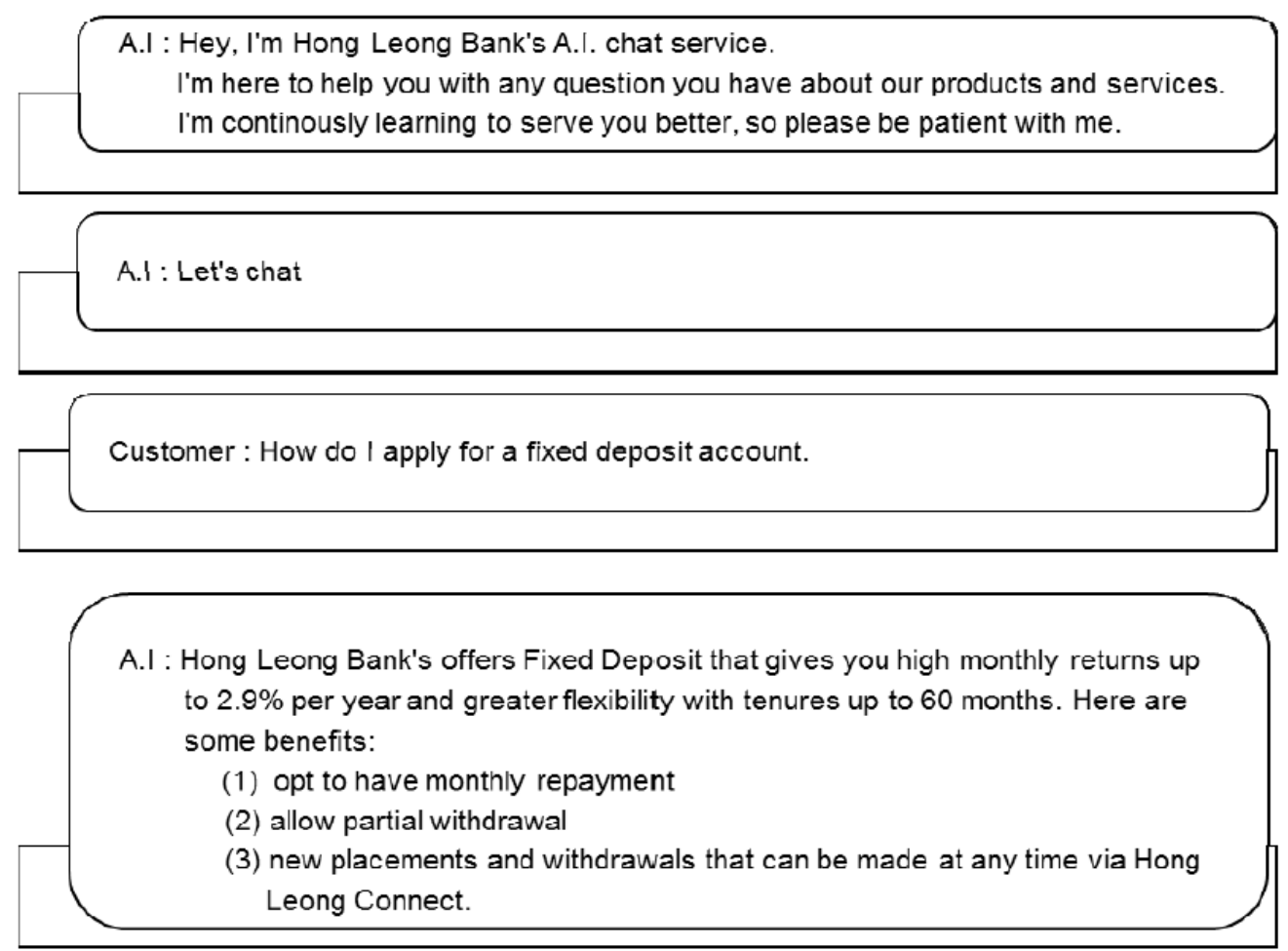

Figure 3. Hong Leong Bank's A.I. chat service

\section{Scenario 2}

"NAO" is a customer service humanoid robot, weighing $5.4 \mathrm{~kg}$ and standing $58 \mathrm{~cm}$ tall which is currently in its 5th version since 2006. It was developed by the French company, recalled as Aldebaran Robotics. This company is a subsidiary of Japanese telecom and technology giant, SoftBank Corp. Mitsubishi UFJ Financial Group Inc was thought to be the first financial service industry that employed the "NAO" robot (Marous, 2017). Figure 4 shown the robot named "NAO" at Mitsubishi UFJ Financial Group Inc in Japan. The "NAO" robot works at the reception area. The main task is to welcome the guests and provides them with information in a variety of languages. The "NAO" robots are also able to demonstrate kung fu moves and dance while greeting customers and handing out bankers' business cards. The cost is approximately $\$ 8,000$ and lasts 12 hours between charges.

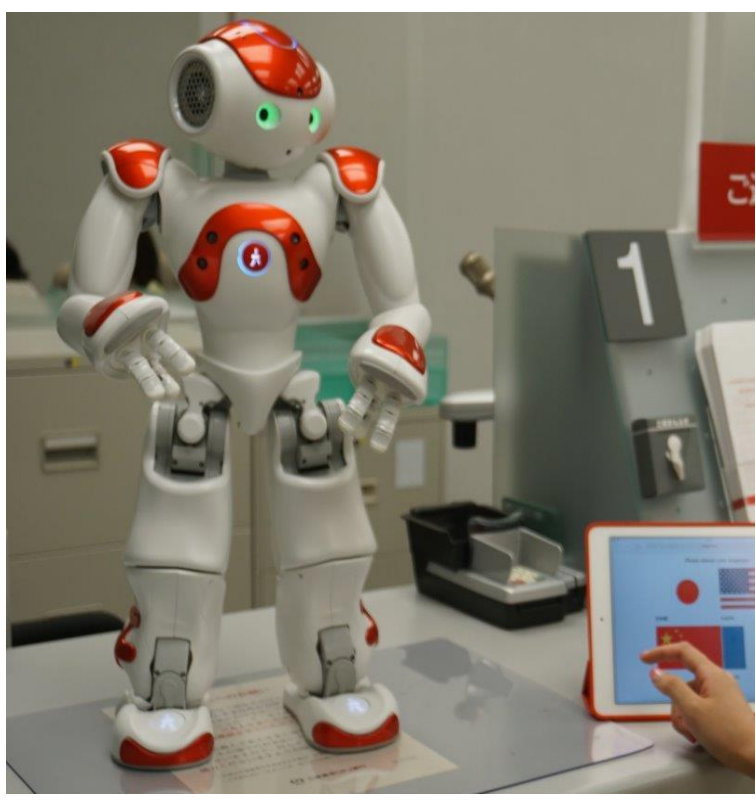

Figure 4. The "NAO" humanoid robot 


\section{Scenario 3}

Another examples, Mizuho bank use "Pepper" to display the important information about their company. Figure 5 clearly show the robot named "Pepper" deploy at the Mizuho Bank in Japan (Softbank Robotics, 2017). It has an interactive tablet that helps augment communication with users. "Peppers" are connected to the cloud, which allows them to constantly learn new things. The good news about "Pepper" it can store information while interacting with customers on the cloud for future analysis. Pepper stands just 4 feet tall and weight of only $28 \mathrm{~kg}$. Pepper have been installed together with a 3D camera and 10 inch touch screen. Right now, Pepper robot is selling for JPY 198,000 or USD\$1,900. With the installation of 3D camera, "Pepper" able to detect customer movement and understand human emotions. "Peppers" respond with simulations of emotions like joy, anger and irritation. It became available to Japanese consumers in June 2015. Since then, approximately 1,000 units of robot have gone on sale every month.

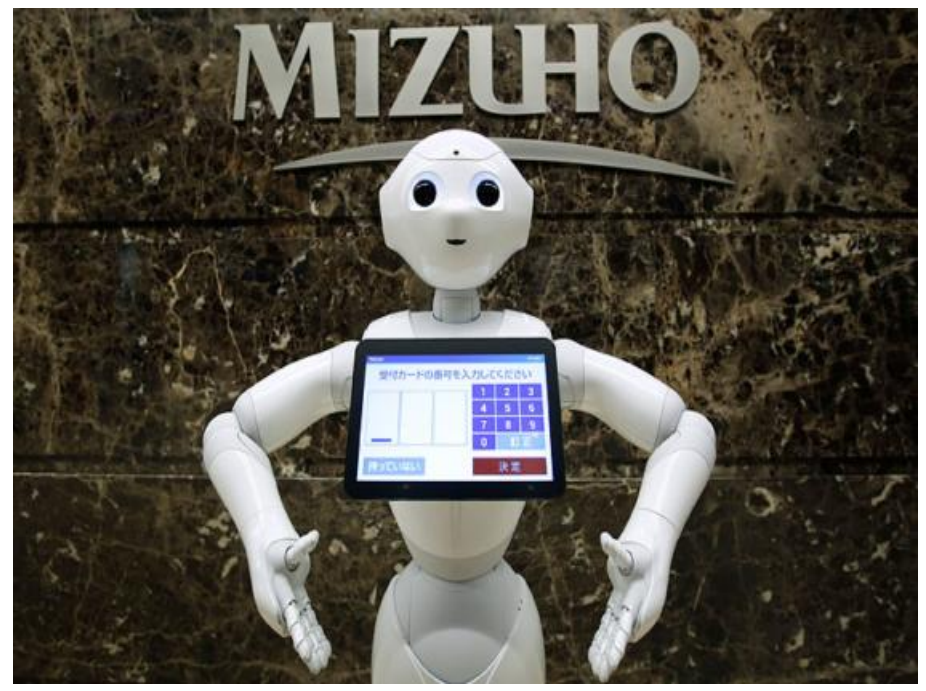

Figure 5. Robot "Pepper"

\section{Advantages of Artificial Intelligence (AI)}

Some of the main advantages of artificial intelligence are listed below:

\section{(a) Reducing Error}

AI offers an opportunity to achieve accuracy with a higher degree of precision and this consequently enable to minimize the human errors. Indeed, the cognitive technology error is very rare compared to human errors. In the healthcare industry, AI have been employed to optimize the clinical procedure. Normally, healthcare professionals give prescription based on questioning and routine check-ups. However, in most of the times healthcare professional are unable to attend a large number of cases at one time. This might create a chance for errors. Delegation of duties to AI are meant for medical error that made by human due to excessive work pressure.

Jiang, Jiang, Zhi, et al. (2017) believe that AI not only assist physicians to make better clinical decision, it might even replace human judgment such as in the radiology area. Another aspect related to the issue, AI reduce errors in banking services by minimizing the human involvement in cyber, fraud, compliance, credit and internal audit. The data inputs in AI are able to differentiate good transactions from fraudulent ones, which easily be overlooked by humans. V Maslamani, the Chief Compliance officer of Al Rajhi Bank of Saudi Arabia at the Conference on Financial Crime and Terrorism Financing (IFCTF) 2017 admitted that AI will reduce cost and human error.

Another examples, the recent case of West Wind Aviation Flight 280 on 13 December 2017 inspired the development of AI technology in the airlines industry. This would allow airlines to use artificial intelligence (AI) autopilot in very complex airline operations. Haitham Baomar and Peter Bentley who led the invention of AI autopilot at University College London intend to reduce the human error factors that might be caused by stress, information overload, lack of sufficient and up-to-date training.

\section{(b) Multi-tasking}

Tasks can be classified into routine or non-routine tasks. Repetitive tasks which are monotonous in nature can be 
carried out with the help of machine intelligence. Machines think faster than humans and can be put to multi-tasking. For example, the same neural network that is designed to filter out spam e-mails may reuse its knowledge in detecting the phishing attempts, prioritize the inbox in accordance to importance, and assist in drafting the responses to common requests. AI offers keep more information than paper based filing. The huge dataset space to help users to upload multi-task information and find information. In any case, multi-tasking improves the performance of manufacturing company. Today, AI able to perform various task from forklift drivers to product design and quality assurance. With this advanced technology, it is beneficial to the manufacturing industry as it lower the labour cost and reduce dependency on low skilled labour.

\section{(c) Work for longer hours}

Unlike human, AI are programmed for long hours. AI could change the fast food industry. AI will soon affect every dining experience including preparing the meal, taking orders and delivery. The innovation in digital capability enable the customer to experience a non-stop service from the fast food industry. Other example of AI is the automated teller machine that able to replace the working hours of bank clerk and auto call centers that able to pick up your call at any time. Undeniable, we are heading to a rapid technology growth and taking advantages of AI.

\section{Application of Smart Contract}

Traditional contract do not occur exclusively via technology. It is relatively straightforward to identify when an offer has been made and accepted by examining the words and conduct of the parties along with all relevant circumstances. Alternatively, a smart contract has a potential to become a legal contract if certain conditions are met. How do smart contract works? The terms of the contracts are coded in computer algorithm as a set of instructions that will be automatically execute the next step until the entire transaction cycle completes. This smart contract allows immutable, verifiable and secure record of all contracts and transactions which are fully auditable. It designed in a complex set of software codes with the instruction to automate execution and settlement of contractual agreement.

Figure 6 explains further about the smart contract where the process began once there is agreement between parties (i.e. option conract). The data is stored on every computer in the network which is written as code into the blockchain. The smart contract will definitely trigger the important events such as the expiration date and strike price. This information is recorded and the smart contract executes itself according to the coded terms. If two or more parties agreed agreed upon the terms and conditions within the contract, they cryptographically sign the smart contract and deploy it to a distributed ledger. Later on, once the specific code is met, the program automatically runs a corresponding action. The final stage are imposed by regulators. Thus, regulators can use the blockchain in maintaing the privacy of the individual actors' position.

Figure 7 illustrates the process of smart contract. The pre-defined smart contract sets the specific conditions such as the rights and obligations to which the parties of a protocol or smart contract consent to. The events trigger the execution of the contract. This events refer to the transaction initiated and information received. Subsequently, the terms of contract dictate movement of value based on conditions met. As for the settlement, there are two options available (i) on-chain assets (digital) and (ii) off-chain assets (physical). For digital assets on the chain, the smart contract opts for crypto-currency (Bitcoin, Ethereum, Lite Coin, Ripple, Dash, NEM, NEO or Monera) As a consequence, payment transactions occur automatically. For physical assets, the smart contract requires stocks and fiat money. Beyond simple encryption and integrity checks, this system will make changes to specific accounts reflected on the ledger. The transactions simultaneously updating the match off-chain settlement instructions.

Smart contract could support the Islamic finance products. The terms and legal conditions are specific in legal documents and must be executed in the correct order to ensure the compliance to Shariah. In other words, smart contracts, would streamline the operations of Islamic financial institutions and automate the entire contractual process. Smart contracts is expected to support the Islamic banking industry in several areas, alike Islamic capital markets and investment banking (sukuk, Islamic stock exchange, Islamic wealth management), Islamic bank (trade finance, Islamic REIT's, crowd-funding) and takaful industry (automated claims, renewal of general takaful products).

In fact, Malaysian Digital Economy Corp (MDEC) is looking forward to launched "Islamic Digital Economy Framework" by March 2018. MDEC is working closely with Jabatan Kemajuan Islam Malaysia (Jakim) and Amanie Advisors Sdn Bhd to formulate the framework. This framework will serves as a guideline for venture capitals to run a business. Specifically, the paper by Khan (2017) identity the applications of smart contracts with Islamic capital markets, inheritance law and loans. By doing so, smart contracts would bring takaful operators, 
bankers, customers and third parties to a single platform that will lead to process efficiencies, and reduce claim processing time and costs.

Step 1: Smart contract in written code

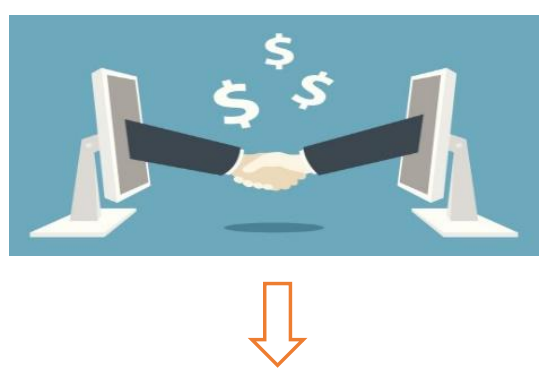

Step 2: Program automatically runs a corresponding action

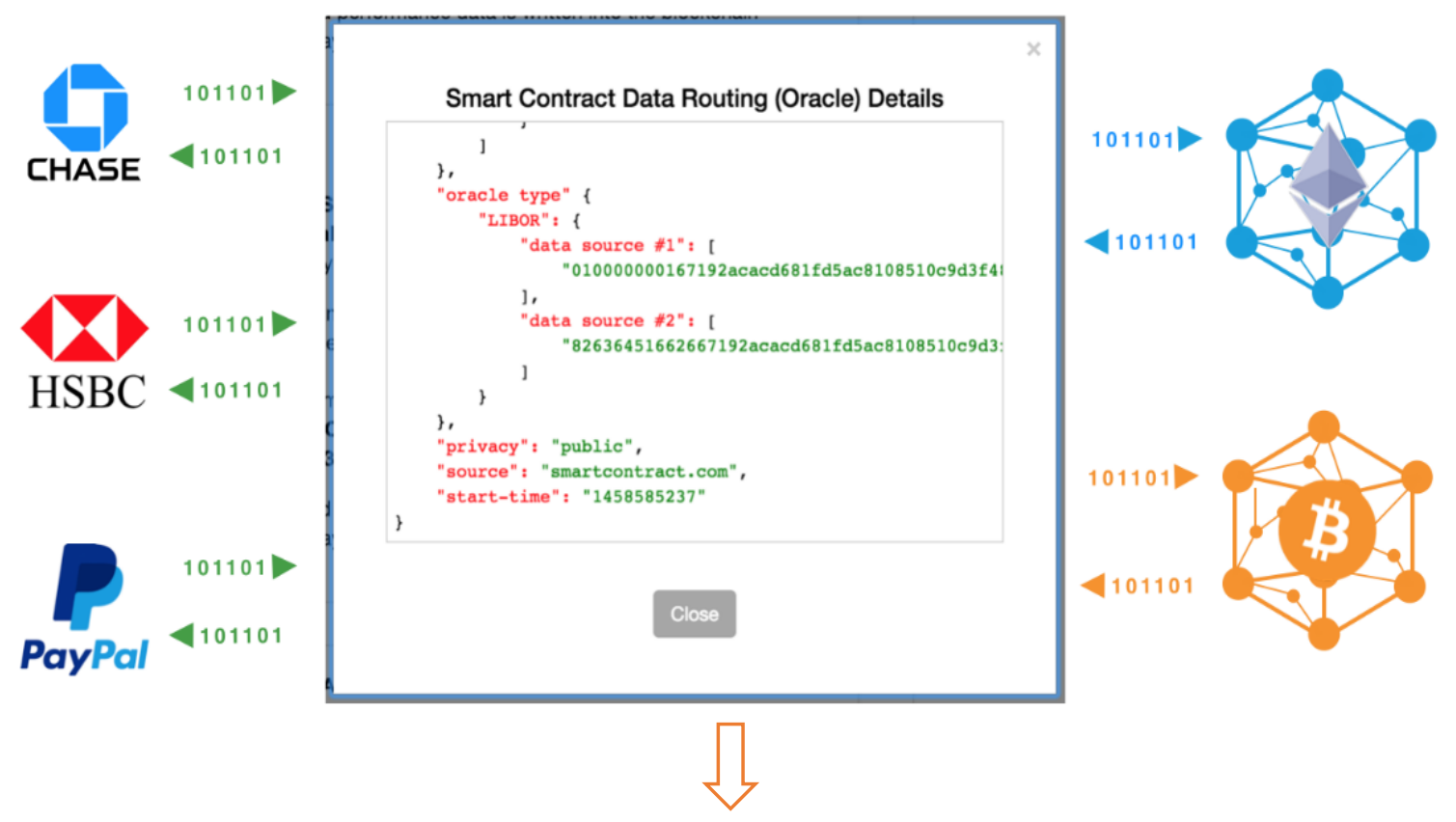

Step 3: Imposed regulators activities

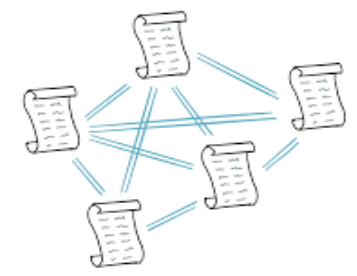

Figure 6. Scenario of Smart Contract

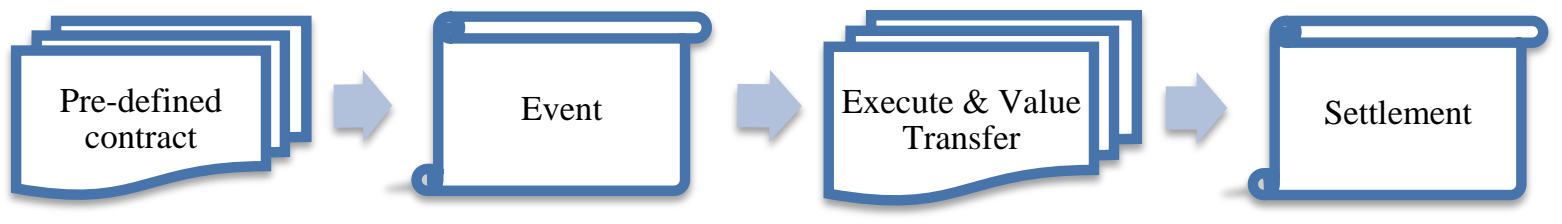

Figure 7. Process Flow of Smart Contract 


\section{Advantages of Smart Contract}

The advantages of smart contract to any other kind of agreement, among others includes:

(a) Efficiency

Smart contract operate better when there is a rich data set that can be derived from existing information. Each term and condition of the contract need to be coded accordingly. The transaction will only be visible to people or parties related to the contract.

(b) Transparency

The transparency will make business-to-business (B2B) transactions easier. This simplifies exchanges and reduces the need for participation from banks, lawyers and middlemen.

\section{Conclusion}

The digital smart contract effectively replace traditional forms of paper contracts. Smart contract helps to improve to a more credible transaction without jeopardizing authenticity and its credibility. Undoubtedly, digital smart contracts have the potential to revolutionize the trade and banking industry. Similarly, the idea of artificial intelligence will not only improve the way we think or live our lives and also to explore new horizons. One can imagine that artificial intelligence and smart contract helps to improve chances of reaching accuracy. At the same time, it works on minimizing errors in the organization and data management. With banking embracing the new technology, bank customers can hope for a better banking experience and fulfilling their rising expectations.

\section{References}

Abdullah, O. (2017, October 3). Digitalization in Islamic Finance. Retrieved from http://kliff.com.my/wpcontent/uploads/2016/09/Sesi-3-Digitalization-of-Islami-Finance-Othman.pdf.

Alzaidi, A., \& Kazakov, D. (2008). Artificial Intelligence for Islamic Banking. Journal of Muamalat and Islamic Finance Research, 5(1), 1-15.

Bogue, R. (2014). The Role of Artificial Intelligence in Robotics. Industrial Robot: An International Journal, 4l(2), 119-123. https://doi.org/10.1108/IR-01-2014-0300

Dirican, C. (2015). The Impacts of Robotics, Artificial Intelligence on Business and Economics. Procedia Social and Behavioral Sciences, 95, 564-573. https://doi.org/10.1016/j.sbspro.2015.06.134

Finley, K. (2017, December 12). A $\$ 50$ million Hack just showed that the DAO was all too human. Retrieved from https://www.wired.com/2016/06/50-million-hack-just-showed-dao-human/.

Giancaspro, M. (2017). Is a 'smart contract' really a smart idea? Insights from a legal perspective. Computer Law \& Security Review, 33, 825-835. https://doi.org/10.1016/j.clsr.2017.05.007

Hamet, P., \& Tremblay, J. (2017). Artificial Intelligence in Medicine. Metabolism Clinical and Experimental, 69, 36-40. https://doi.org/10.1016/j.metabol.2017.01.011

Hassabis, D., Kumaran, D., Summerfield, C., \& Botvinick, M. (2017). Neuroscience Inspired Artificial Intelligence. Neuron, 19(2), 245-258. https://doi.org/10.1016/j.neuron.2017.06.011

Idelberger, F., Governatori, G., Riveret, R., \& Sartor, G. (2016). Evaluation of Logic-Based Smart Contracts for Blockchain Systems. Rule Technologies. Research, Tools, and Applications, 10th International Symposium (pp. 167-183). New York, United States: Springer, Cham. https://doi.org/10.1007/978-3-319-42019-6_11

Jiang, F., Jiang, Y., Zhi, H., et al. (2017). Artificial intelligence in healthcare: past, present and future. Stroke and Vascular Neurology. http://dx.doi.org/10.1136/svn-2017-000101

Khan, N. (2017, December 13). The Impact of Financial Technology. Retrieved from https://www.linkedin.com/ pulse/impact-financial-technology-nida-khan

Kmeid, R. (2017, December 13). Islamic Banker. Retrieved from Will Artificial Intelligence rejuvenate Islamic finance? https://www.islamicbanker.co/2017/08/31/will-artificial-intelligence-rejuvenate-islamic-finance/

Ligaya, A. (2017, December 23). Financial Post. Retrieved from Rise of the robot: How banks are using artificial intelligence upfront and behind the scenes. Retrieved from http://business.financialpost.com/ news/fp-street/rise-of-the-robot-banks-using-artificial-intelligence-upfront-and-behind-the-scenes

Marous, J. (2017, December 22). Robots and AI invade banking. Retrieved from The Financial Brand. https://thefinancialbrand.com/52735/robots-artificial-intelligence-ai-banking/ 
Mik, E. (2017). Smart Contracts: Terminalogy, technical limitations and real world complexity. Law, Innovation and Technology, 9, 296-300. https://doi.org/10.1080/17579961.2017.1378468

Narrative Science. (2016). Outlook on Artificial Intelligence in the Enterprise 2016. Chicago: Narrative Science.

Pan, Y. (2016). Heading toward Artificial Intelligence 2.0. Engineering, 2(4), 409-413. https://doi.org/10.1016/J.ENG.2016.04.018

Research and Markets. (2017). Artificial Intelligence Market: Global Forecast to 2020. Ireland: Research and Markets. Retrieved from https://www.researchandmarkets.com/reports/3979203/artificial-intelligencechipsets-market-by

Savelyev, A. (2017). Contract law 2.0: 'Smart' contracts as the beginning of the end of classic contract law. Information \& Communications Technology Law, 26(2), 116-134. https://doi.org/10.1080/13600834.2017. 1301036

Softbank Robotics. (2017, December 22). Who is Pepper? Retrieved from https://www.ald.softbankrobotics. com/en/robots/nao

Steve, \& Laser, T. (2017, December 22). Nissan Hires 100 Robots for its Dealers in Japan: "Pepper" Droid Greets Customers. Retrieved from https://www.carnichiwa.com/car-news/nissan-hires-100-robots-for-itsdealers-in-japan-pepper-droid-greets-customers/

Szabo, N. (1997). Formalizing and Securing Relationships on Public Networks. First Monday, 2(9), http://firstmonday.org/ojs/index.php/fm/article/view/548/469. http://dx.doi.org/10.5210/fm.v2i9.548

\section{Copyrights}

Copyright for this article is retained by the author(s), with first publication rights granted to the journal.

This is an open-access article distributed under the terms and conditions of the Creative Commons Attribution license (http://creativecommons.org/licenses/by/4.0/). 